\title{
Can the Zero-Profile Implant Be Used for Anterior Cervi- cal Discectomy and Fusion in Traumatic Subaxial Disc Injury? A Preliminary, Retrospective Study
}

Tae Hun Kim, M.D., ${ }^{1}$ Dae Hyun Kim, M.D., Ph.D., ${ }^{1}$ Ki Hong Kim, M.D., Ph.D., ${ }^{1}$ Young Seok Kwak, M.D., ${ }^{1}$ Sang Gyu Kwak, Ph.D., ${ }^{2}$ Man Kyu Choi, M.D., Ph.D.'

Departments of Neurosurgery, Medical Statistics, ${ }^{2}$ Daegu Catholic University Medical Center, Catholic University of Daegu College of Medicine, Daegu, Korea

Objective : The zero-profile implant (Zero-P) is accepted for use in anterior cervical fusion for the treatment of degenerative cervical disease. However, evidence pertaining to its efficiency and safety in traumatic cervical injury is largely insufficient. This study aimed to compare the overall outcomes of patients who underwent Zero-P for traumatic cervical disc injury.

Methods : Data from a total of 53 consecutive patients who underwent surgery for traumatic or degenerative cervical disc disease using the Zero-P were reviewed. Seventeen patients (group A) had traumatic cervical disc injury and the remaining 36 (group B) had degenerative cervical disc herniation. The fusion and subsidence rates and Cobb angle were measured retrospectively from plain radiographs. The patients' clinical outcomes were evaluated using the Japanese Orthopedic Association (JOA) score and Odom's criteria.

Results : The C2 -7 Cobb and operative segmental angles increased by $3.45 \pm 7.61$ and $2.94 \pm 4.59$ in group $A$; and $2.46 \pm 7.31$ and $2.88 \pm 5.49$ in group B over 12 postoperative months, respectively. The subsidence and fusion rate was $35.0 \%$ and $95.0 \%$ in group A; and $36.6 \%$ and $95.1 \%$ in group $B$, respectively. None of the parameters differed significantly between groups. The clinical outcomes were similar in both groups in terms of increasing the JOA score and producing a grade higher than "good" using Odom's criteria.

Conclusion : The application of Zero-P in patients with traumatic cervical disc injury was found to be acceptable when compared with the clinical and radiological outcomes of degenerative cervical spondylosis.

Key Words : Cervical vertebrae · Spinal cord trauma · Allograft.

- Received : April 19, 2018 •Revised : June 20, 2018 •Accepted : June 25, 2018

- Address for reprints : Man Kyu Choi, M.D., Ph.D.

Department of Neurosurgery, Daegu Catholic University Medical Center, Catholic University of Daegu College of Medicine, 33 Duryugongwon-ro 17-gil, Nam-gu, Daegu 42472, Korea

Tel : +82-53-650-3495, Fax : +82-53-650-4932, E-mail : spinechoi@cu.ac.kr

This is an Open Access article distributed under the terms of the Creative Commons Attribution Non-Commercial License (http://creativecommons.org/licenses/by-nc/4.0) which permits unrestricted non-commercial use, distribution, and reproduction in any medium, provided the original work is properly cited. 


\section{INTRODUCTION}

Anterior cervical decompression and fusion (ACDF) is an effective method for the treatment of traumatic and/or degenerative disc lesion because neurologic compressions usually occur anteriorly. Although various modified techniques of ACDF have been developed since it was first described by Smith and Robinson ${ }^{15)}$, the outcomes of these procedures remain controversial. Traditionally, iliac bone graft with anterior plating was used for ACDF in order to stabilize the cervical spine and promote bone union ${ }^{9,10)}$. Additionally, a stand-alone cage was often used to avoid the donor site morbidity and plate-related complications including esophageal injury, screw pullout, and plate migration that can occur in traditional $\mathrm{ACDF}^{5,6)}$.

The zero-profile interbody fusion device, Zero-P (Synthes GmbH, Oberdorf, Switzerland) was invented to reduce platerelated complications. It consists of an interbody spacer and locking screws that can be fixed in the intervertebral space. It has been shown to provide similar biomechanical stability to the use of a cage and anterior plating system ${ }^{13)}$. The same conclusion was drawn from a study involving patients with degenerative pathology, and the Zero-P has been used in ACDF for the treatment of degenerative cervical disease ${ }^{14)}$. However, these previous studies did not provide sufficient evidence on the efficiency or safety of Zero-P in traumatic cervical disc injury. There has been only one preliminary study on the outcomes of ACDF using Zero-P in subaxial cervical spine trauma ${ }^{3)}$.

In the present study, we performed a retrospective analysis to compare the clinical and radiologic outcomes achieved with ACDF using Zero-P for traumatic cervical disc injury to those achieved for degenerative cervical spondylosis. In addition, Zero-P was used in selected patients with traumatic injury who had no bony fracture, severe segmental instability, or kyphotic deformity requiring posterior instrumentation.

\section{MATERIALS AND METHODS}

\section{Patient population}

We retrospectively reviewed data from patients treated for ACDF using the Zero-P in our clinic between January 2013 and December 2016. A total of 53 patients were enrolled in this study. Of the 53 patients, 17 were treated with only Zero-P, i.e., without posterior fixation for traumatic disc injury (group A), and the remaining 36 patients were treated for degenerative disc herniation (group B). Surgical indicated levels were a single segment or skipped two segments (not including contiguous two segments, such as C3/4/5), determined by evaluating the preoperative radiologic pathology and clinical symptoms. Patients who met any of the following criteria were excluded in group A : 1) vertebral body fracture, 2) facet dislocation, and 3) cases requiring posterior decompression and instrumentation, such as severe canal stenosis and kyphotic deformity. In addition, the following criteria were also excluded in group A and B as well : 1) prior cervical spine surgery, 2) autoimmune or metabolic bone disease, and 3) postoperative surgical site infection.

In group $\mathrm{A}$, the presence of a paravertebral ligament injury, prevertebral hemorrhage, facet perch and the score from the Sub-axial Cervical Spine Injury Classification System (SLICS) were further evaluated through medical charts, operation re-

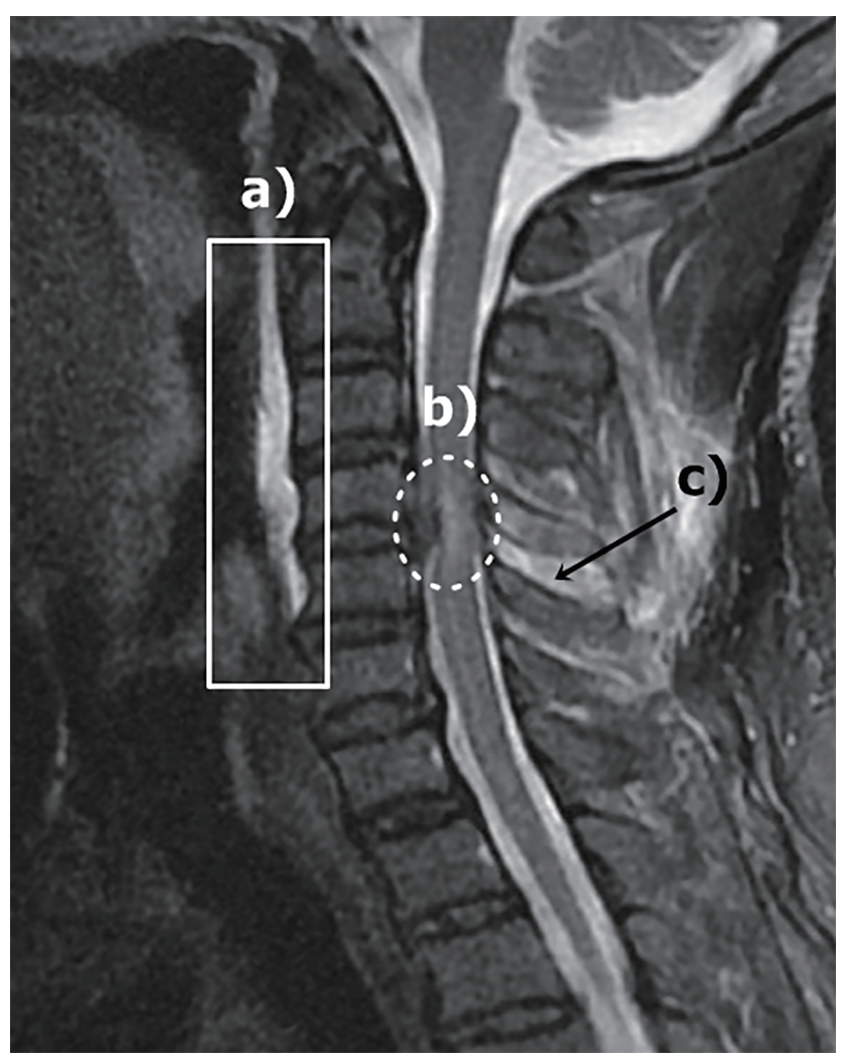

Fig. 1. Magnetic resonance imaging of the patients revealed the type of associated traumatic cervical injury : a) prevertebral hemorrhage; b) signal change of the cervical cord; and c) suspicious injury of the interspinous ligament. 
cords, and preoperative magnetic resonance imaging (Fig. 1).

\section{Surgical techniques}

For ACDF using Zero-P, the patient was placed in the supine position under general anesthesia. Fluoroscopy was used to confirm the target level. A horizontal incision was made along the skin crease in the neck that correlated to the target cervical disc. After removal of the intervertebral disc with a careful endplate preparation, generous decompression of the bilateral neuroforamen was performed. A Kerrison punch and high-speed electric drill were used to decompress the nerve roots by removing the osteophyte overgrowth on the uncovertebral joint and posterior lips of the vertebral body. Extensive saline irrigation was performed during drilling of the osteophytes and milling of the endplates. After sufficient decompression, we applied a Zero-P convex implant and 4 Zero-P screws under intraoperative fluoroscopy. After the release of a Casper distractor, a manual pullout test was conducted to confirm the stability of the segments. A closed system drainage catheter was placed. After surgery, all patients were instructed to wear a Philadelphia neck brace for 4 weeks.

\section{Radiological evaluation}

Radiological images were assessed pre-operation and at follow-ups that occurred approximately 3, 6, and 12 months postoperatively. The cervical curvature angle, fusion status, and subsidence rate was assessed using cervical X-ray and cervical computed tomography (CT). All radiographic reports were interpreted and measured using PACS system software (INFINITT, Seoul, Korea).

The cervical Cobb angle was measured as the acute angle constructed by the lines running along each inferior vertebral endplate of the $\mathrm{C} 2$ and $\mathrm{C} 7$ vertebral bodies on lateral X-ray. The operative segmental angle was measured as the acute angle constructed by the lines running along the superior and inferior vertebral endplates of the operated vertebral body. The difference between the pre-operative and 12-month postoperative follow-up angles for each parameter was designated as the delta $(\triangle)$ value (Fig. 2).

The evaluation of fusion of the operated cervical vertebral body was determined using dynamic cervical X-ray 12 months postoperatively. In cases in which it was difficult to determine the fusion status accurately by plain radiograph, the trabecu- lar bone bridge was checked using cervical CT (Fig. 3). The protocol for bone fusion was as follows : 1) magnify image $>150 \%$; 2) assess for adequate flexion-extension effort by confirming that there is $>4 \mathrm{~mm}$ of inter-spinous process motion at a non-arthrodesed level; and 3) ensure there is $<1 \mathrm{~mm}$ of inter-spinous process motion at the fused level ${ }^{17}$.

Cage subsidence was defined as a decrease in interbody height $>3 \mathrm{~mm}$ on a plain radiograph 12 months postoperatively. The difference in subsidence was based on the length between the center of the upper and lower endplates in a lateral X-ray.

\section{Clinical evaluation}

The clinical outcomes were evaluated pre- and postoperatively and at the last follow-up using the Japanese Orthopedic Association (JOA) score. At the last follow-up, patients were

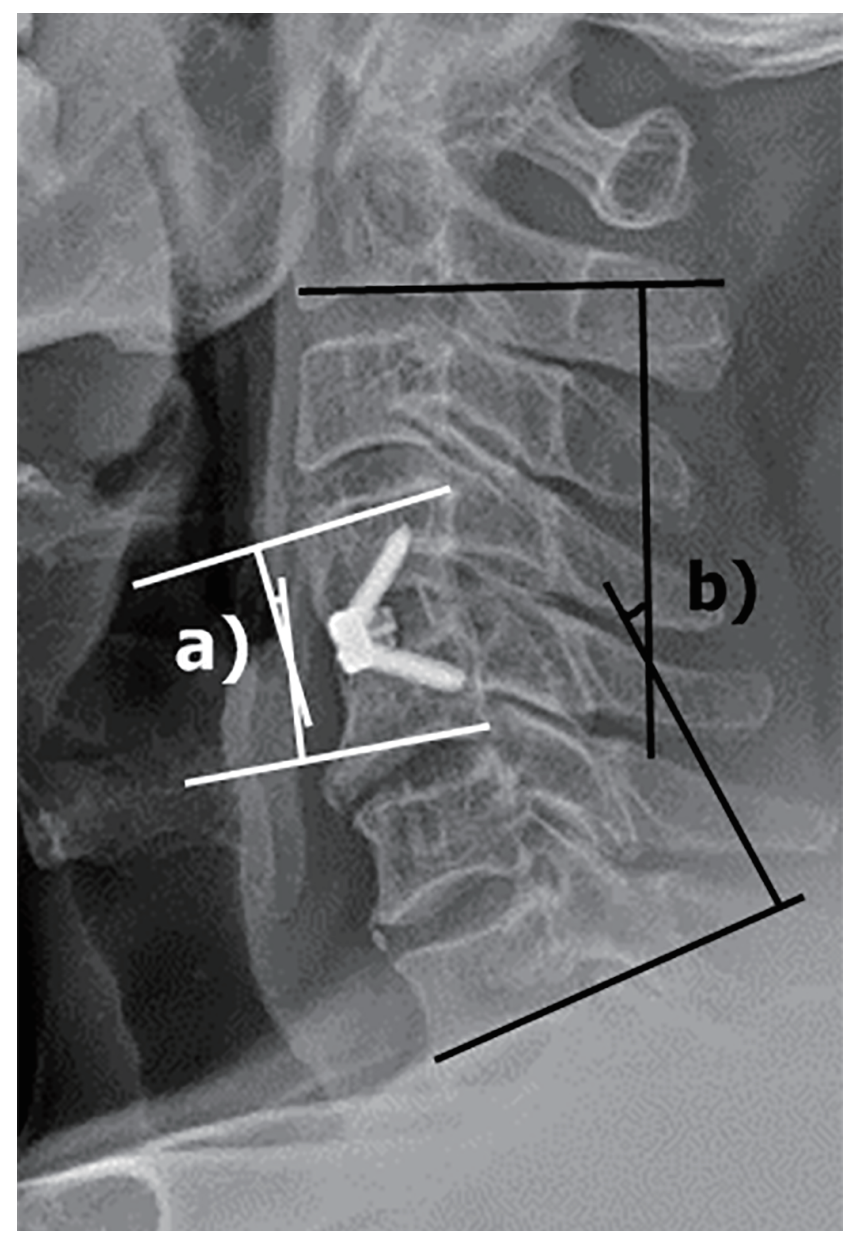

Fig. 2. Measurement of the cervical sagittal alignment : a) operative segmental angle; b) Cobb's angle. 
assessed according to Odom's criteria, which ranging from ratings of excellent to poor ${ }^{12)}$.

\section{Statistical analysis}

Patient characteristics and clinical outcomes were assessed using descriptive analyses, with the mean (standard deviation) and median (interquartile range) presented for quantitative variables and the frequency (percent) presented for qualitative variables. The comparison of characteristics and clinical outcomes between groups A and B were analyzed using twosample t-tests or Mann-Whitney U tests for quantitative variables and chi-square tests or Fisher's exact test for qualitative variables. $p$-values are presented for all statistically significant variables. All statistical analyses were performed using the SPSS software package for Windows version 19.0 (IBM, Chicago, IL, USA). All tests were 2 -sided, and $p$-values $<0.05$ were

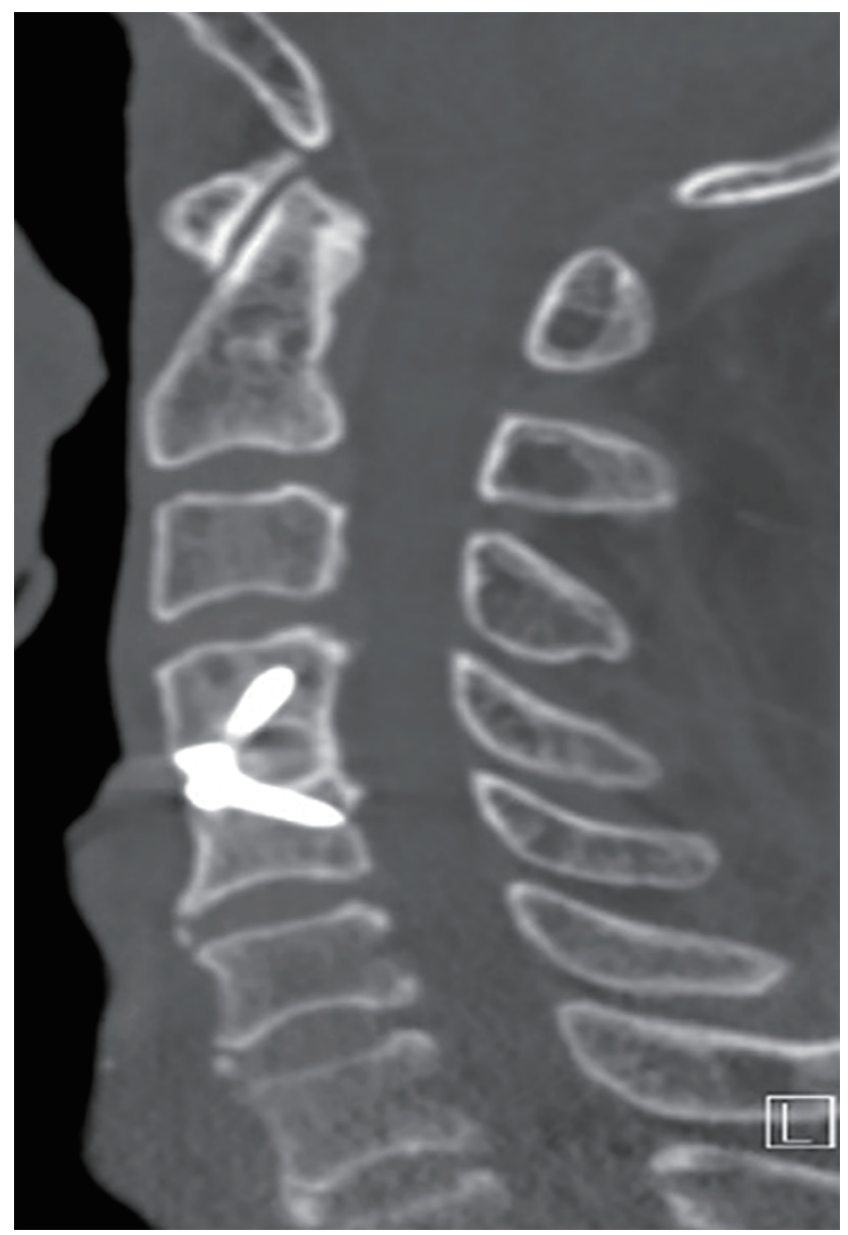

Fig. 3. Computed tomography showed additional new bone formation with bony bridging across the disc space. considered to indicate statistical significance.

\section{RESULTS}

\section{Demographic data of the patients enrolled in the study}

A total of 53 patients who underwent fusion using a Zero-P were enrolled in the study. Group A consisted of 16 men and one woman (mean age, 53.9 years). During the same period, 17 men and 19 women (mean age, 57.0 years) were enrolled in group B (Table 1). In group A, all patients had an interspinous ligament injury, and the incidence of anterior longitudinal ligament injury was higher than that of posterior longitudinal ligament injury. Prevertebral hemorrhage was observed in all patients except one, facet perch was observed in only two patients, and cord signal change was observed in 14 patients (14/17, 76.5\%). The SLICS score was at least four points in group A, with five points occurring most frequently. Other detailed data for group A are presented in Table 2.

\section{Radiological outcomes}

The fusion rate was $95.0 \%$ (19/20) in group A and 95.1\% (39/41) in group B. The mean Cobb and operative segmental angles increased by $3.45 \mathrm{~mm}$ and $2.94 \mathrm{~mm}$, respectively, over the preoperative value in group A. Similarly, the Cobb and operative segmental angles increased by $2.46 \mathrm{~mm}$ and 2.88 $\mathrm{mm}$, respectively, in group B. Cage subsidence occurred in 7 levels $(7 / 20,35.0 \%)$ in group A and 12 levels (12/41, 29.3\%) in

Table 1. Demographic data of the study population

\begin{tabular}{lccc} 
& Group A & Group B & $\boldsymbol{p}$-value \\
\hline Patients & 17 & 36 & \\
Operated level & 20 & 41 & $0.929^{*}$ \\
$\quad 1$ level & 14 & 31 & \\
$\quad$ Skipped 2 levels & 3 & 5 & \\
Sex & 16 & 17 & $0.001^{\dagger}$ \\
$\quad$ Male & 1 & 19 & \\
Female & 53.9 & 57 & $0.432^{\ddagger}$ \\
Age (years) & 21.6 & 19.6 & $0.701^{\ddagger}$ \\
Mean follow-up period & & & \\
(months) & & & \\
\hline
\end{tabular}

* Fisher's exact test. ${ }^{\dagger}$ Chi-square test. ${ }^{\ddagger}$ Mann-Whitney U test 
Table 2. Detailed demographic data of the patients with traumatic disc injury (group A)

\begin{tabular}{|c|c|c|c|c|c|c|c|c|c|c|}
\hline \multirow{2}{*}{ No } & \multirow{2}{*}{$\begin{array}{l}\text { Sex/age } \\
\text { (years) }\end{array}$} & \multirow{2}{*}{ Levels } & \multicolumn{3}{|c|}{ Ligament injury } & \multirow{2}{*}{$\begin{array}{l}\text { Facet } \\
\text { perch }\end{array}$} & \multirow{2}{*}{$\begin{array}{l}\text { Prevertebral } \\
\text { hemorrhage }\end{array}$} & \multirow{2}{*}{$\begin{array}{l}\text { Cord signal } \\
\text { change }\end{array}$} & \multirow{2}{*}{ SLIC score } & \multirow{2}{*}{ JOA score } \\
\hline & & & ALL & PLL & ISL & & & & & \\
\hline 1 & $M / 46$ & $C 5-6$ & $x$ & $x$ & 0 & $x$ & 0 & 0 & 5 & 16 \\
\hline 2 & $M / 53$ & C3-4/5-6 & $x$ & $x$ & 0 & $x$ & 0 & 0 & 5 & 11 \\
\hline 3 & $M / 45$ & C5-6 & 0 & $x$ & 0 & 0 & 0 & 0 & 6 & 9 \\
\hline 4 & $F / 76$ & C5-6 & $x$ & 0 & 0 & $x$ & 0 & 0 & 5 & 13 \\
\hline 5 & $M / 61$ & C6-7 & 0 & $x$ & 0 & $x$ & 0 & $x$ & 5 & 11 \\
\hline 6 & $M / 44$ & C6-7 & 0 & $x$ & 0 & $x$ & 0 & $x$ & 5 & 16 \\
\hline 7 & $M / 22$ & C $3-4$ & 0 & $x$ & 0 & $x$ & 0 & $x$ & 5 & 15 \\
\hline 8 & $M / 60$ & C $3-4$ & 0 & 0 & 0 & $x$ & 0 & 0 & 5 & 14 \\
\hline 9 & $M / 54$ & C5-6 & 0 & $x$ & 0 & $x$ & 0 & $x$ & 5 & 16 \\
\hline 10 & $\mathrm{M} / 51$ & C $3-4$ & $x$ & $x$ & 0 & $x$ & 0 & 0 & 5 & 14 \\
\hline 11 & $\mathrm{M} / 42$ & $C 3-4 / 5-6$ & $x$ & $x$ & 0 & $x$ & 0 & 0 & 5 & 9 \\
\hline 12 & $\mathrm{M} / 58$ & C6-7 & $x$ & $x$ & 0 & $x$ & $x$ & 0 & 5 & 14 \\
\hline 13 & $M / 72$ & $C 5-6$ & 0 & $x$ & 0 & $x$ & 0 & 0 & 6 & 10 \\
\hline 14 & $M / 45$ & $(3-4 / 5-6$ & 0 & $x$ & 0 & $x$ & 0 & 0 & 5 & 9 \\
\hline 15 & M/61 & C4-5 & 0 & $x$ & 0 & $x$ & 0 & 0 & 4 & 6 \\
\hline 16 & $\mathrm{M} / 53$ & $(4-5$ & 0 & $x$ & 0 & 0 & 0 & 0 & 6 & 15 \\
\hline 17 & $\mathrm{M} / 73$ & C6-7 & 0 & 0 & 0 & $x$ & 0 & 0 & 4 & 16 \\
\hline
\end{tabular}

No : number, ALL : anterior longitudinal ligament, PLL : posterior longitudinal ligament, ISL : interspinous ligament, SLIC : subaxial injury classification, JOA : Japanese Orthopedic Association, $\mathrm{M}$ : male, $\mathrm{X}$ : absence, $\mathrm{O}$ : presence, $\mathrm{F}$ : female

Table 3. Comparisons of radiologic outcomes stratified by cervical plain radiographs

\begin{tabular}{|c|c|c|c|}
\hline & $\begin{array}{c}\text { Group A } \\
\text { (levels, 20) }\end{array}$ & $\begin{array}{l}\text { Group B } \\
\text { (levels, 41) }\end{array}$ & $p$-value \\
\hline \multicolumn{4}{|l|}{ Operated level } \\
\hline $\mathrm{C} 3 / 4$ & 6 & 8 & $0.360^{*}$ \\
\hline$C 4 / 5$ & 2 & 8 & $0.346^{*}$ \\
\hline$C 5 / 6$ & 8 & 22 & $0.316^{\dagger}$ \\
\hline $\mathrm{C} 6 / 7$ & 4 & 3 & $0.145^{*}$ \\
\hline Fusion & 19/20 (95.0) & 39/41 (95.1) & $0.984^{*}$ \\
\hline$\Delta C 2-C 7$ Cobb angle $\left(^{\circ}\right)$ & $3.45 \pm 7.61$ & $2.46 \pm 7.31$ & $0.987^{\ddagger}$ \\
\hline $\begin{array}{l}\Delta \text { Operative segmental } \\
\text { angle }\left(^{\circ}\right)\end{array}$ & $2.94 \pm 4.59$ & $2.88 \pm 5.49$ & $0.072^{\S}$ \\
\hline Subsidence & $7 / 20(35.0)$ & $12 / 41(29.3)$ & $0.650^{\dagger}$ \\
\hline
\end{tabular}

Values are presented as mean \pm standard deviation or number (\%). *Fisher's exact test. ${ }^{\dagger}$ Chi-square test. ${ }^{\ddagger}$ Mann-Whitney $U$ test. ${ }^{\S}$ Twosample t-test. $\Delta$ : value 12 months postoperatively-preoperative value

group B. None of the measured values were significantly different between the two groups (all $p>0.05$, Table 3 ).

\section{Clinical outcomes stratified by JOA score and Odom's criteria}

Both groups exhibited an improvement in clinical outcomes as demonstrated by the increase from the mean preoperative JOA score to the postoperative JOA scores (JOA; group A, 1.59 \pm 1.58 ; group $B, 1.44 \pm 1.05$ ). There were no statistically significant differences with regard to the JOA values between the two groups ( $p=0.696$ ). According to Odom's criteria, all outcomes had a grade higher than "good" in both groups. There vwere no significant differences in the proportions of "good" outcomes between the two groups ( $p=0.667$, Table 4 ).

\section{Comparisons of radiologic and clinical outcomes in male patients}

We performed a comparative analysis of male subjects in both groups, because group A was mostly consisted of male patients $(16 / 17,94.1 \%)$ and the number was similar to male patients in group B. In terms of radiologic and clinical outcomes, there were no significant differences between male subjects of group A and B. Detailed data for comparisons of 
Table 4. Comparisons of clinical outcomes stratified by JOA and Odom's criteria

\begin{tabular}{lccc}
\hline & $\begin{array}{c}\text { Group A } \\
(\mathbf{n}=7)\end{array}$ & $\begin{array}{c}\text { Group B } \\
(\mathbf{n}=36)\end{array}$ & $p$-value \\
\hline$\triangle \mathrm{JOA}$ & $1.59 \pm 1.58$ & $1.44 \pm 1.05$ & $0.696^{*}$ \\
Odom's criteria & & & \\
Excellent & 3 & 12 & \\
Good & 11 & 20 & \\
Fair & 3 & 3 & \\
Poor & 0 & 1 & \\
\hline
\end{tabular}

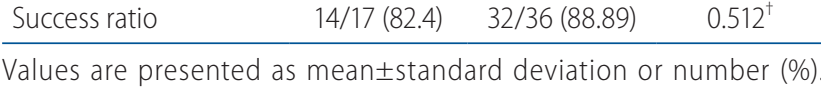

*Two-sample t-test. ${ }^{\dagger}$ Fisher's exact test. JOA : Japanese Orthopedic Association, $\Delta$ : value 12 months postoperatively-preoperative value

both groups are presented in Table 5 .

\section{Complications}

Three patients (two in group A and one in group B) suffered from transient dysphagia, but recovered within 3 weeks postoperation. In group B, one patient reported prolonged vocal cord paralysis. No complications requiring re-operation, such as surgical site infection, instrumental failure, or postoperative hematoma, occurred.

\section{DISCUSSION}

Traumatic cervical injury is a common problem in adults and has a male predominance. The purpose of surgical treatment is the prevention of additional functional loss, the maintenance of neurological function, and the restoration of spinal stability with bone union ${ }^{1,7)}$. ACDF with or without posterior fixation has become the most suitable surgery for traumatic cervical injury. The rationale for the use of the cage-plate system in ACDF is that patients who undergo these implants are more likely to require only minimal external bracing and return to normal activities earlier than those who undergo cervical fusion surgery without plating. There are also theoretical benefits, such as initial stability, improved bone fusion, prevention of bone graft collapse, or extrusion and maintenance of sagittal alignment. However, plate-related complications, such as esophagus injury and postoperative dysphagia, can occur $^{8,18)}$.
Table 5. Comparisons of radiologic and clinical outcomes in male patients

\begin{tabular}{|c|c|c|c|}
\hline & $\begin{array}{c}\text { Males in } \\
\text { group A } \\
(n=16, \\
\text { levels=19) }\end{array}$ & $\begin{array}{c}\text { Males in } \\
\text { group B } \\
(n=17, \\
\text { levels=20) }\end{array}$ & $p$-value \\
\hline Fusion & $18 / 19(94.7)$ & $19 / 20(95.0)$ & $0.970^{*}$ \\
\hline$\Delta C 2-C 7$ Cobb angle $\left(^{\circ}\right)$ & $3.41 \pm 7.52$ & $2.21 \pm 7.12$ & $0.830^{\dagger}$ \\
\hline $\begin{array}{l}\Delta \text { Operative segmental } \\
\text { angle }\left(^{\circ}\right)\end{array}$ & $2.82 \pm 4.43$ & $2.61 \pm 4.93$ & $0.082^{\dagger}$ \\
\hline Subsidence & $7 / 19(36.8)$ & $5 / 20(25.0)$ & $0.423^{\ddagger}$ \\
\hline$\triangle J O A$ & $1.55 \pm 1.56$ & $1.53 \pm 1.17$ & $0.743^{\dagger}$ \\
\hline $\begin{array}{l}\text { Success ratio (Odom's } \\
\text { criteria) }\end{array}$ & $13 / 16(81.3)$ & 15/17 (88.2) & $0.576^{*}$ \\
\hline
\end{tabular}

Values are presented as mean \pm standard deviation or number (\%). *Fisher's exact test. ${ }^{\dagger}$ Mann-Whitney $U$ test. ${ }^{~}$ Chi-square test. $\Delta$ : value 12 months postoperatively-preoperative value, JOA : Japanese Orthopedic Association

Zero-P implants feature a design that fixes the existing stand-alone cage onto the vertebral body with a screw, thereby reducing plate-related complications. Many studies have evaluated the efficacy and safety of the Zero-P implant. Barbagallo et al. found that the Zero-P was associated with good clinical outcomes, such as low rates of neck disability, postoperative dysphagia, and fusion time ${ }^{2}$. Additionally, Njoku et al. ${ }^{11}$ reported that the Zero-P had clinical outcomes and radiologic fusion rates comparable with the cage-plate system. Most studies have assessed the postoperative outcomes of ACDF using Zero-P in cases of degenerative cervical spondylosis, Zero-P has been accepted as a useful graft for ACDF in degenerative cervical disc disease ${ }^{2,4,11,14,16)}$. Based on these previous studies, we used Zero-P as a graft for ACDF in cases of traumatic disc injury. In the present study, Zero-P was used in selected patients with traumatic injury who had no bony fracture, severe segmental instability, or kyphotic deformity requiring posterior instrumentation.

A major concern of ACDF using Zero-P in traumatic injury is the risk of cage subsidence, pseudoarthrosis, and sagittal malalignment. In our series, we focused on objectively comparing these values. The subsidence rate of patients with traumatic injury (group A) was $35.0 \%$, which was similar to the subsidence rate of degenerative spondylosis patients (group B, 29.3\%). The fusion rate was $95.0 \%$ in group $A$ and $95.1 \%$ in group $B$, and there were few differences between the two groups. In addition, sagittal alignment, including the Cobb 
angle and the segmental angle, was well maintained postoperatively. Although the number of enrolled patients was small, similar radiologic outcomes were obtained in a study of ACDF using Zero-P in 12 patients with subaxial cervical spine trauma (fusion rate, 100\%; no sagittal malalignment) ${ }^{3)}$.

Clinical outcomes such as neck and radicular pain, as well as other neurologic deficits, were alleviated when compared to the patients' preoperative symptoms 12 months postoperatively. The increase in JOA scores and the proportion of grades higher than "good" using Odom's criteria were similar in both groups. In addition, the number of patients who suffered from plate-related complications was very low in both groups.

However, we acknowledge the following limitations to our study : 1) the number of patients in the traumatic injury (group A) was relatively small; 2) the follow-up period was relatively short; 3) biomechanical testing was lacking; and 4) the limited inclusion criteria applied to the traumatic injury group were often very subjective and are not backed by scientific literature. Nevertheless, we observed similar fusion and subsidence rates in both groups along with correct sagittal alignment. Clinically, most of the patients (from either group) with neurologic deficit and pain improved after surgery. Finally, we had no patients with chronic dysphagia. Though there were some limitations to our study, we believe that our case series supports the initiation of prospective trials involving multiple centers, larger patient populations, and longer follow-up periods.

\section{CONCLUSION}

Based on the results of our study, the overall outcomes achieved for ACDF using Zero-P in cases of traumatic injury were satisfactory and comparable to those achieved in cases of degenerative spondylosis. Therefore, Zero-P implantation in selected patients may be a useful alternative graft option for ACDF in traumatic disc injury.

\section{CONFLICTS OF INTEREST}

No potential conflict of interest relevant to this article was reported.

\section{INFORMED CONSENT}

Informed consent was obtained from all individual participants included in this study.

\section{References}

1. Aebi M : Surgical treatment of upper, middle and lower cervical injuries and non-unions by anterior procedures. Eur Spine J 19 Suppl 1 : S33S39, 2010

2. Barbagallo GM, Romano D, Certo F, Milone P, Albanese V : Zero-P: a new zero-profile cage-plate device for single and multilevel ACDF. A single institution series with four years maximum follow-up and review of the literature on zero-profile devices. Eur Spine J 22 Suppl 6 : S868- S878, 2013

3. Brembilla C, Lanterna LA, Gritti P, Signorelli A, Biroli $F$ : The use of a stand-alone interbody fusion cage in subaxial cervical spine trauma: a preliminary report. J Neurol Surg A Cent Eur Neurosurg 76 : 13-19, 2015

4. Cho HJ, Hur JW, Lee JB, Han JS, Cho TH, Park JY : Cervical stand-alone polyetheretherketone cage versus zero-profile anchored spacer in singlelevel anterior cervical discectomy and fusion : minimum 2-year assessment of radiographic and clinical outcome. J Korean Neurosurg Soc 58 : 119-124, 2015

5. Choi MK, Kim SB, Park CK, Kim SM : Comparison of the clinical and radiologic outcomes obtained with single- versus two-level anterior cervical decompression and fusion using stand-alone PEEK cages filled with allograft. Acta Neurochir (Wien) $158:$ 481-487, 2016

6. Choi MK, Kim SB, Park CK, Lee SH, Jo DJ : Relation of deep paraspinal muscles' cross-sectional area of the cervical spine and bone union in anterior cervical decompression and fusion: a retrospective study. World Neurosurg $96:$ 91-100, 2016

7. Glaser JA, Jaworski BA, Cuddy BG, Albert TJ, Hollowell JP, McLain RF, et al. : Variation in surgical opinion regarding management of selected cervical spine injuries. A preliminary study. Spine (Phila Pa 1976) 23 : 975-982; discussion 983, 1998

8. Halani SH, Baum GR, Riley JP, Pradilla G, Refai D, Rodts GE Jr, et al. : Esophageal perforation after anterior cervical spine surgery: a systematic review of the literature. J Neurosurg Spine 25 : 285-291, 2016

9. Kaiser MG, Haid RW Jr, Subach BR, Barnes B, Rodts GE Jr : Anterior cervical plating enhances arthrodesis after discectomy and fusion with cortical allograft. Neurosurgery 50 : 229-236; discussion 236-238, 2002

10. Lowery GL, McDonough RF : The significance of hardware failure in anterior cervical plate fixation. Patients with 2- to 7-year follow-up. Spine (Phila Pa 1976) 23 : 181-186; discussion 186-187, 1998

11. Njoku I Jr, Alimi M, Leng LZ, Shin BJ, James AR, Bhangoo S, et al. : Anterior cervical discectomy and fusion with a zero-profile integrated 
plate and spacer device: a clinical and radiological study: clinical article. J Neurosurg Spine 21 : 529-537, 2014

12. Odom GL, Finney W, Woodhall B : Cervical disk lesions. J Am Med Assoc $166: 23-28,1958$

13. Scholz M, Reyes PM, Schleicher P, Sawa AG, Baek S, Kandziora F, et al. : A new stand-alone cervical anterior interbody fusion device: biomechanical comparison with established anterior cervical fixation devices. Spine (Phila Pa 1976) 34 : 156-160, 2009

14. Shao H, Chen J, Ru B, Yan F, Zhang J, Xu S, et al. : Zero-profile implant versus conventional cage-plate implant in anterior cervical discectomy and fusion for the treatment of degenerative cervical spondylosis: a meta-analysis. J Orthop Surg Res 10 : 148, 2015

15. Smith GW, Robinson RA : The treatment of certain cervical-spine disorders by anterior removal of the intervertebral disc and interbody fusion.
J Bone Joint Surg Am 40-A : 607-624, 1958

16. Son DK, Son DW, Kim HS, Sung SK, Lee SW, Song GS : Comparative study of clinical and radiological outcomes of a zero-profile device concerning reduced postoperative Dysphagia after single level anterior cervical discectomy and fusion. J Korean Neurosurg Soc 56 : $103-$ 107, 2014

17. Song KS, Piyaskulkaew C, Chuntarapas T, Buchowski JM, Kim HJ, Park MS, et al. : Dynamic radiographic criteria for detecting pseudarthrosis following anterior cervical arthrodesis. J Bone Joint Surg Am 96 : 557-563, 2014

18. Wang T, Ma L, Yang DL, Wang H, Bai ZL, Zhang LJ, et al. : Factors predicting dysphagia after anterior cervical surgery: a multicenter retrospective study for 2 years of follow-up. Medicine (Baltimore) 96 : e7916, 2017 